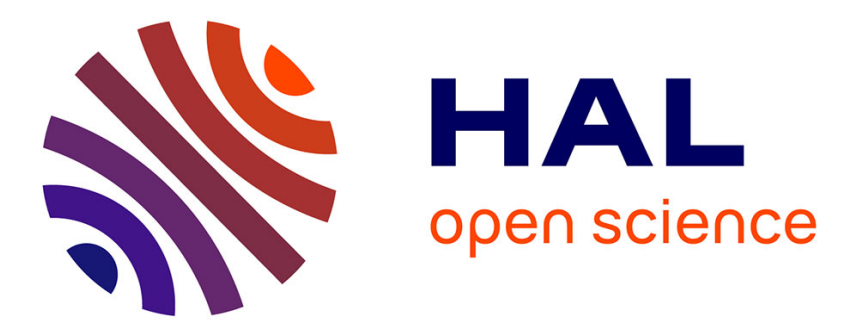

\title{
Methyl Adenine Identification (MadID): High-Resolution Detection of Protein-DNA Interactions
}

David Umlauf, Michal Sobecki, Laure Crabbe

\section{To cite this version:}

David Umlauf, Michal Sobecki, Laure Crabbe. Methyl Adenine Identification (MadID): HighResolution Detection of Protein-DNA Interactions. The nucleus, 2175, pp.123-138, 2020, Methods in Molecular Biology book series, 10.1007/978-1-0716-0763-3_10 . hal-03014022

\section{HAL Id: hal-03014022 \\ https://hal.science/hal-03014022}

Submitted on 19 Nov 2020

HAL is a multi-disciplinary open access archive for the deposit and dissemination of scientific research documents, whether they are published or not. The documents may come from teaching and research institutions in France or abroad, or from public or private research centers.
L'archive ouverte pluridisciplinaire HAL, est destinée au dépôt et à la diffusion de documents scientifiques de niveau recherche, publiés ou non, émanant des établissements d'enseignement et de recherche français ou étrangers, des laboratoires publics ou privés. 
Methyl Adenine Identification (MadID): High-resolution detection of protein-DNA interactions.

Umlauf David $^{1}$, Michal Sobecki ${ }^{2}$ and Laure Crabbe ${ }^{1}$

${ }^{1}$ LBCMCP, Centre de Biologie Integrative (CBI), CNRS, Université de Toulouse, UT3, Toulouse 31062, France. ${ }^{2}$ Institute of Anatomy, University of Zurich, Winterthurerstrasse 190, CH-8057 Zurich, Switzerland. 


\begin{abstract}
Mapping the binding sites of DNA- or chromatin-interacting proteins is essential to understand many essential biological processes. Methyl Adenine Identification (MadID) is a proximity methylation-based assay that allows the visualization, quantification, and identification of binding sites from DNAinteracting proteins in eukaryotic cells. Chromatin-binding proteins of interest are fused to the newly described bacterial methyltransferase M.EcoGII. This enzyme catalyses the methylation of adenine residues with no sequence specificity. Consequently, adenines within and in the vicinity of the protein binding sites will be decorated with a methyl group (m6A), modification that can be further detected using different methods. M.EcoGII-dependent DNA methylation can be monitored in situ using immunostaining, at the genome-wide level using a combination of m6A-specific immunoprecipitation and whole-genome sequencing or locally at DNA regions of interest purified by chromatin immunoprecipitation or probe-based capture techniques. MadID is conceptually similar to DNA adenine methyltransferase identification (DamID) that relies on the methylation of GATC motifs. However, MadID provides a higher resolution, deeper coverage, and open the ways to identification of binding sites in genomic regions that were largely inaccessible such as telomeres, centromeres and repeated elements.
\end{abstract}


Keywords: MadID, DamID, m6A, proximity labelling, M.EcoGII, Telomeres, Centromeres, LADs, Dotblot, High-throughput sequencing. 
During interphase, chromatin folding in the three dimensional space of eukaryotic nuclei as well as the composition of the chromatin fiber itself are key to understand genome regulation. Chromatin immunoprecipitation (ChIP) has long been the method of choice to characterize interactions between proteins and DNA allowing access to chromatin composition [1]. However, ChIP entirely relies on the availability of ChIP-grade antibodies and is incompatible with the detection of transient interactions. Here, we present MadID, a proximity-labelling technique that circumvents these limitations and allows the mapping of protein-DNA interactions with various experimental setups [2].

MadID is an optimized method based on DNA adenine methyltransferase identification (DamID), which has emerged as a comprehensive technique to map genome-wide occupancy of proteins of interest [3]. DamID uses the ability of the bacterial Dam methyltransferase to methylate adenine residues within GATC motifs. When fused to a chromatin binding protein in an inducible system, this enzyme targets the methylation of GATC motifs residing within and in the vicinity of the protein binding sites. DamID has been instrumental in unveiling nuclear organization of specific parts of the genome such as Lamin Associated Domains (LADs) [4-6] and has also been successfully applied to study genome organization on a global scale (see for example [7]). Overall, DamID is a powerful approach that allows the study of chromatin composition and its dynamics. However, it is inherently limited by its dependence on the distribution of the GATC tetrameric recognition site, which represents only $0.9 \%$ of the human genome [2]. In addition, several genomic regions are deprived or poor in the GATC motifs required for Damdependent methylation, such as AT-rich regions, telomeres, or centromeres, which are therefore blind to DamID.

To overcome these limitations, we took advantage of the newly described M.EcoGII methyltransferase from E. coli to implement MadID. Unlike site-specific methyltransferases such as Dam, M.EcoGII methylates adenine residues in any DNA sequence context with a high efficiency [8]. Consequently, GATC-null or GATC-poor regions are now fully accessible to MadID, which constitutes an unbiased strategy to map protein-DNA interactions with a deeper coverage and higher resolution [2]. Fused to a protein of interest, M.EcoGII drives adenine methylation (m6A) at the protein binding site, 
methylation that can be further analysed by a variety of methods. M.EcoGII was successfully targeted in human cells to telomeres, centromeres, and the nuclear envelope using fusion proteins with TRF1, Centromeric Protein C, and LaminB1, respectively [2] (plasmids available at Addgene, see materials). However, MadID can be implemented in any model organism in which transgenesis is feasible, and for any protein of interest provided the fusion with M.EcoGII remains functional.

In this method chapter we present a detailed protocol of MadID, from the generation of cells expressing the M.EcoGII-fusion proteins using retroviral transduction, to the different readouts available to assess, quantify or map DNA methylation: i) m6A detection in situ by indirect immunostaining using a m6A antibody, including a protocol to combine this detection with DNA-FISH, ii) genome-wide m6A detection after m6A-immunoprecipitation (m6A-IP) followed by high-throughput sequencing, and iii) detection of m6A on a dotblot (m6A-dotblot) with total genomic DNA or after purification of a particular DNA regions of interest. We provide the method for telomere purification using a probe-based capture technique as an example. 


\subsection{Generation of cells expressing M.EcoGII constructs}

1. Plasmids from Sobecki et al. available at Addgene.

- $\quad$ pRetroX-PTuner-DD-linker-M.EcoGII (\#122082)

- $\quad$ pRetroX-PTuner-DD-linker-M.EcoGII-v5-Lamin B1 (\#122083)

- $\quad$ pRetroX-PTuner-DD-M.EcoGII-v5-TRF1 (\#122084)

- $\quad$ pRetroX-PTuner DD-M.EcoGII-v5-Centromeric protein C (\#122085)

2. Shield-1 10mM in Ethanol 100\% (Aobious). Working stock at 1mM.

3. Phoenix amphotropic cell line (ATCC CRL-3213) that express amphotropic envelope protein for the generation of helper-free amphotropic retroviruses.

4. Cell line of interest and the appropriate medium and supplements for culturing the cell line.

5. Dulbecco's Phosphate-buffered saline (PBS) no calcium no magnesium, $\mathrm{pH}$ 7.4.

6. Trypsin-EDTA solution.

7. Chloroquine.

8. Polybrene.

9. 2X HBS: 50mM HEPES pH 7.05, $10 \mathrm{mM} \mathrm{KCl,} 12 \mathrm{mM}$ Dextrose, $280 \mathrm{mM} \mathrm{NaCl}, 1.5 \mathrm{mM}$ $\mathrm{Na} 2 \mathrm{HPO} 4$ (FW 141.96). Filter sterilize, aliquot and store at $-20^{\circ} \mathrm{C}$ for up to 6 months.

10. $2 \mathrm{M} \mathrm{CaCl2}$. Filter sterilize, aliquot and store at $-20^{\circ} \mathrm{C}$.

11. Puromycin.

\section{2. m6Adenine immunofluorescence}

1. Parafilm.

2. Coverslips (e.g., $12 \mathrm{~mm}$ coverslips 1.5 from Menzel-Gläzer).

3. Microscope slides (e.g., $25 \times 75 \times 1.0 \mathrm{~mm}$ slides from VWR).

4. Fixation buffer: $4 \%$ Paraformaldehyde in PBS $1 \mathrm{X}$ no methanol, (e.g., $16 \%$ solution electron microscopy grade from Electron Microscopy Sciences).

5. Dulbecco's Phosphate-buffered saline (PBS), $\mathrm{pH}$ 7.0-7.3.

6. Permeabilization buffer: $0.5 \%$ TritonX100 in PBS 1X.

7. RNaseA $10 \mathrm{mg} / \mathrm{ml}$. 
8. RNase cocktail Enzyme Mix (Ambion).

9. Denaturation buffer: $1.5 \mathrm{M} \mathrm{NaCl}, 0.5 \mathrm{M} \mathrm{NaOH}$.

10. Neutralization buffer: $0.5 \mathrm{M}$ Tris- $\mathrm{HCl} \mathrm{pH} 7.0,3 \mathrm{M} \mathrm{NaCl}$.

11. Blocking solution: $0.2 \%(\mathrm{w} / \mathrm{v})$ cold water fish gelatin, $0.5 \%(\mathrm{w} / \mathrm{v})$ Bovine Serum Albumin (BSA) in PBS 1X. Filter sterilize, aliquot and store at $-20^{\circ} \mathrm{C}$.

12. Rabbit Anti N6-methyladenosine antibody (Synaptic System, \#202 003).

\subsection{DNA Fluorescence In Situ Hybridization (FISH)}

1. Fixation buffer: $4 \%$ Paraformaldehyde in PBS $1 \mathrm{X}$ no methanol, (e.g., $16 \%$ solution electron microscopy grade from Electron Microscopy Sciences).

2. Molecular biology grade ethanol.

3. PNA probe(s) complementary to the sequence(s) of interest, (e.g., PNA probes from Panagene).

4. Blocking solution: Prepared from blocking reagent for nucleic acid hybridization and detection (e.g. Roche) using manufacturer's recommendation.

5. Hybridization mix: $10 \mathrm{mM}$ Tris- $\mathrm{HCl} \mathrm{pH} 7.2,70 \%$ deionized formamide, $0.5 \%$ blocking solution. Aliquot and store at $-20^{\circ} \mathrm{C}$.

6. Heating block.

7. Incubation chamber (e.g. $245 \mathrm{~mm}$ X $245 \mathrm{~mm}$ Dish Corning).

8. Wash buffer I: $0,01 \mathrm{M}$ Tris- $\mathrm{HCl} \mathrm{pH} 7.2,0.1 \% \mathrm{BSA}, 70 \%$ formamide.

9. Wash buffer II: 0,01 M Tris- $\mathrm{HCl} \mathrm{pH} 7.2,0.15 \mathrm{M} \mathrm{NaCl}, 0.08 \%$ Tween ${ }^{\circledR 2}$.

10. DAPI.

11. Antifade mounting medium.

\subsection{Genomic DNA extraction}

1. QIAGEN Blood and Cell Culture DNA Midi Kit Genomic-tip 100/G from QIAGEN.

2. RNase A.

3. RNase Cocktail Enzyme Mix (Ambion).

4. Fluorometer apparatus to accurately measure DNA concentration (e.g., QUBIT fluorometer from Thermo Fisher Scientific). 


\section{5. m6Adenine immunoprecipitation (m6A-IP) followed by high throughput sequencing}

1. A sonication apparatus (e.g., Bioruptor Sonicator from Diagenode equipped with a water cooler).

2. Polypropylene tubes (TPX) from Diagenode.

3. NEBNext End-repair module (New England Biolabs).

4. NEBNext A-tailing module (New England Biolabs).

5. Double stranded TruSeq adapters (Illumina).

6. NEBNext Ligation module (New England Biolabs).

7. TE buffer: $10 \mathrm{mM}$ Tris-HCl pH 8.0, $1 \mathrm{mM}$ EDTA.

8. 10X m6A-IP buffer: $100 \mathrm{mM}$ Na-Phosphate buffer $\mathrm{pH}$ 7.0, 3M NaCL, 0.5\% TritonX100.

9. Rabbit Anti N6-methyladenosine antibody (Synaptic System, \#202 003).

10. Protein A/G Dynabeads mix (Thermo Fisher Scientific).

11. Pre-blocking buffer: PBS $1 \mathrm{X}, 0.5 \%$ BSA, $0.1 \%$ Tween 20 .

12. Digestion buffer: $50 \mathrm{mM}$ Tris- $\mathrm{HCl} \mathrm{pH} 8.0,10 \mathrm{mM}$ EDTA, 0.5\% SDS.

13. Proteinase $\mathrm{K}$ at $20 \mathrm{mg} / \mathrm{ml}$.

14. Phenol:chloroform:iso-amylalcohol 25:24:1 (v/v/v).

15. KAPA Hifi DNA polymerase (Kapa Biosystem).

16. $\mathrm{P} 5$ and $\mathrm{P} 7$ primers (Illumina).

17. AMPureXB beads (Beckmann Coulter).

\section{6. m6A immunodot (m6A-dotblot) detection}

1. BioRad 96-well Bio-Dot apparatus.

2. Amersham Hybond-N+ membrane (GE Healthcare).

3. Whatman filter papers (e.g., Bio-Dot SF Filter Paper from BioRad).

4. 20X SSC.

5. A thermomixer.

6. Denaturing solution: $1.5 \mathrm{M} \mathrm{NaCl}, 0.5 \mathrm{M} \mathrm{NaOH}$.

7. Neutralization solution: $0.5 \mathrm{M}$ Tris- $\mathrm{HCl} \mathrm{pH} .7 .0,0.3 \mathrm{M} \mathrm{NaCl}$. 
8. A UV crosslinker apparatus (e.g., UVC500 UV Crosslinker from Hoefer).

9. 1X Tris Buffered Saline 0.1\% Tween solution (TBST): $20 \mathrm{mM}$ Tris-Base $\mathrm{pH}$ 7.4-7.6, 150 $\mathrm{mM} \mathrm{NaCl}, 0.1 \%$ Tween 20 .

10. Blocking solution: $5 \%$ non-fat dry milk in $1 \mathrm{X}$ TBST.

11. Rabbit Anti N6-methyladenosine antibody (Synaptic System, \#202 003).

12. Goat anti-rabbit Horseradish Peroxidase (HRP) antibody (Promega).

13. Western-ECL substrate Blot imaging System (e.g. Chemidoc Biorad).

\subsection{Telomere purification by TeloCapture}

1. AluI, HinfI, HphI and MnlI restriction enzymes (New England Biolabs).

2. 20X sodium chloride-sodium citrate (SSC): $3 \mathrm{M} \mathrm{NaCl}$ and $300 \mathrm{mM}$ Sodium Citrate equilibrated at $\mathrm{pH}$ 7.0.

3. Triton X100.

4. Biotinylated telomere oligo: Bio-5'-ACTCC(CCCTAA $)_{3}-3$ '.

5. A thermocyler or programmable thermomixer.

6. Streptavidin-coated magnetic beads (Invitrogen M-280).

7. Prewash buffer: $1 \mathrm{X}$ PBS, $0.1 \%$ Tween 20 .

8. 100X Denhardt solution: ( $2 \%$ Ficoll (type- 400$)$, $2 \%$ polyvinylpyrrolidone, $2 \%$ BSA). Filter sterilize, aliquot and store at $-20^{\circ} \mathrm{C}$.

9. End-over-end rotator.

10. Magnetic rack (e.g., DynaMag-2 from life technologies).

11. Wash buffer I: $1 \mathrm{X}$ SSC, $0.1 \%$ TritonX100.

12. Wash buffer II: $0.2 \mathrm{X}$ SSC.

13. Elution buffer: $1 \mathrm{mM}$ Tris pH7.5, 1mM EDTA, 10mMLiCl.

14. Fluorometer apparatus to accurately measure DNA concentration (e.g., QUBIT fluorometer from Thermo Fisher Scientific). 


\subsection{Transfection of Phoenix packaging cells}

1. Grow Phoenix cells in $10 \mathrm{~cm}$ tissue culture dishes to reach about $50-80 \%$ confluency at the time of transfection. Phoenix cells easily detach from the culture dish, therefore be gentle when pipetting medium (see note 1).

2. Transfect cells by calcium phosphate precipitation: prepare a mix in a $1.5 \mathrm{ml}$ microtube with $20 \mu \mathrm{g}$ of plasmid DNA, $62 \mu \mathrm{l}$ of $2 \mathrm{M} \mathrm{CaCl}_{2}$, and $\mathrm{H}_{2} \mathrm{O}$ up to a total of $500 \mu \mathrm{l}$. Add $500 \mu \mathrm{l} 2 \mathrm{X}$ HBS in a $5 \mathrm{ml}$ clear tube. While making bubbles in HBS using a pipette aid, add the $\mathrm{CaCl}_{2} / \mathrm{DNA}$ solution dropwise. Incubate the precipitate for $5 \mathrm{~min}$ at $\mathrm{RT}$.

3. Prepare fresh media containing $25 \mu \mathrm{M}$ of Chloroquine for 12 hours transfection, or $100 \mu \mathrm{M}$ of Chloroquine for a 5 hours transfection.

4. Change the medium of Phoenix cells into $10 \mathrm{ml}$ of chloroquine-containing media. Add the precipitates drop by drop, mix and return the dish to the incubator.

5. Incubate for 5 or 12 hours depending on the chloroquine concentration used. Change into 6 $\mathrm{ml}$ of fresh non-chloroquine containing media.

6. Harvest the virus three times on two consecutive days: collect the cell supernatant and filter through $0.45 \mu \mathrm{m}$ filter. Supernatant can be stored at $-80^{\circ} \mathrm{C}$ for at least a year.

\subsection{Transduction of cells}

1. Seed cells in $10 \mathrm{~cm}$ dishes at $1 \times 10^{6}$ cells per dish (see note 2). Seeding conditions and optimal confluency at the time of transduction are cell type dependent.

2. The next day, change the cell medium with the virus-containing supernatant complemented with $4 \mu \mathrm{g} / \mathrm{ml}$ polybrene and appropriate serum, and incubate overnight.

3. Repeat step 2 twice within 48 hours.

4. The day after the last transduction, add the appropriate antibiotic resistance for selection. 


\subsection{Culture of transduced cells and M.EcoGII constructs induction using Shield-1}

1. Culture the required amount of cells in the appropriate growth medium. Add $1 \mu \mathrm{M}$ of Shield1 to stabilize the DD-tagged M.EcoGII construct. Treat the cells with Shield-1 for a minimum of 6-7 hours, but we recommend 24 hours induction when possible (see note 3).

2. For m6A immunofluorescence (m6A IF), seed cells on glass coverslips using standard procedures (e.g. $5 \times 10^{4}$ to $10^{5}$ cells per well of a 24 well plate containing $500 \mu 1$ of medium and a coverslip). In these conditions, cells are not confluent after induction hence allowing optimal image acquisition following the IF.

3. For m6A immunoprecipitation followed by high throughput sequencing (m6A-IP-seq) as well as for m6A dot-blot, we recommend a minimum of $10-20 \times 10^{6}$ Shield-1 induced cells per condition (i.e. a confluent $15 \mathrm{~cm}$ diameter cell culture dish).

\section{4. m6A immunofluorescence}

1. Prepare the incubation chamber. Cut the appropriate amount of Parafilm and lay it carefully on the surface on the chamber. On both sides of the parafilm, place some tissues previously soaked into water. This will ensure humidification of the chamber during incubation steps.

2. Prepare the primary antibody in blocking solution. We routinely use a 1/250 dilution for the anti-m6A antibody. Unless otherwise specified, a volume of $50 \mu 1$ of diluted antibody is enough to completely cover round coverslips up to $13 \mathrm{~mm}$ in diameter. This volume should be adapted if larger coverslips are used. Washes are usually performed using greater volumes (e.g. $200 \mu 1)$.

3. Carefully remove the medium by aspiration slightly inclining the 24 well plate.

4. Wash cells 5 minutes in $500 \mu 1$ PBS $1 \mathrm{X}$ prior to fixation.

5. Remove the PBS as in 4.

6. Add $500 \mu \mathrm{l}$ of fixation buffer to each well and fix for 10 minutes at room temperature (RT) (see note 4).

7. Wash cells three times 5 minutes in $500 \mu 1$ PBS $1 \mathrm{X}$. In between washes remove the PBS as in 4.

8. Add $500 \mu 1$ of permeabilization buffer and incubate 10 minutes at RT. 
9. Repeat step 8.

10. After the last wash, transfer the coverslips onto the parafilm of the incubation chamber with fine tweezers making sure cells are facing up. Add $200 \mu 1$ of blocking solution supplemented with $200 \mu \mathrm{g} / \mathrm{ml}$ of RNase A and RNase Cocktail Enzyme Mix to a final concentration of $2.5 \mathrm{U} / \mathrm{ml}$ of RNaseA and $100 \mathrm{U} / \mathrm{ml}$ of RNaseT1. Incubate for one hour at $37^{\circ} \mathrm{C}$ (see note 5). Volumes should be as indicated at step 2. From this step onward, it is advisable to add and aspirate solutions from the side of the coverslips.

11. Remove the solution by aspiration and wash cells 5 minutes in $200 \mu 1$ of PBS.

12. Remove the PBS by aspiration. Denature cellular DNA by adding $200 \mu 1$ of denaturing solution per well and leave 30 minutes at RT (see note 6).

13. Remove the denaturing solution by aspiration.

14. Neutralize with $200 \mu 1$ of neutralization solution and incubate 5 min at RT.

15. Remove neutralization solution.

16. Wash cells three times 5 minutes in $200 \mu 1$ PBS $1 X$.

17. Add $200 \mu 1$ blocking solution to each coverslip.

18. Gently aspirate the blocking solution.

19. Add the primary antibody to each coverslip and incubate overnight at $4^{\circ} \mathrm{C}$. Alternatively, incubation can be performed at RT for 2 hours. Volumes should be as indicated at step 2 .

20. Wash coverslips three times $5 \mathrm{~min}$ at RT in blocking solution. In between washes, carefully remove the blocking solution by aspirating on the side.

21. From this step forward protect the coverslips from light.

22. Prepare the secondary antibody in blocking solution. Dilution of the secondary antibodies is at user's discretion. Add the secondary antibody to each coverslip and incubate 45 minutes to one hour at RT. Volumes should be as indicated at step 2 .

23. At this point, if DNA FISH is intended proceed to subheading $\mathbf{3 . 5}$.

24. Wash coverslips twice $5 \mathrm{~min}$ at RT in blocking solution, including $100 \mathrm{ng} / \mathrm{ml}$ DAPI in the second wash, then one additional wash in PBS. In between washes, carefully remove the blocking solution by aspirating on the side. 
25. For mounting, the hereafter steps describe what we are routinely doing in the lab but the reader should be aware that other mounting procedures exist. Pick up the coverslip with fine tweezers, rinse briefly in $\mathrm{ddH} 2 \mathrm{O}$, drain excess water using a tissue and place coverslips (cells facing down) on a $20 \mu 1$ drop of mowiol mounting medium on a microscope slide. Try to avoid trapping of air bubbles.

26. Drain excess of mounting medium with tissue. Leave at RT overnight for the mowiol to dry and then store at $4{ }^{\circ} \mathrm{C}$. Examples of m6A staining can be found in Sobecki et al [2].

\subsection{DNA Fluorescence In Situ Hybridization (FISH) following m6Adenine immunofluorescence}

1. Prepare the probe in hybridization buffer according to the manufacturer's instruction.

2. Heat-up the hot plate and set the temperature to $80^{\circ} \mathrm{C}$.

3. Wash coverslips three times 5 min at RT in blocking solution. In between washes, carefully remove the blocking solution by aspirating on the side.

4. Remove the coverslips from the parafilm with fine tweezers and place them back into a 24well plate containing $500 \mu 1$ of fixation buffer. Fix for 10 minutes at RT (see note 7).

5. Rinse the coverslips twice with $\mathrm{dH}_{2} \mathrm{O}$ (see note 8).

6. Perform ethanol dehydration series by sequentially incubating cells in graded ethanol $70 \%$, ethanol $90 \%$ and ethanol $100 \%$ for 5 minutes.

7. Pick up the coverslips with fine tweezers and make sure they air-dry.

8. On a clean glass slide, place $20 \mu 1$ of working stock of PNA probe and place the coverslip cell side down into the PNA solution. Avoid air bubbles.

9. Denature DNA by placing the coverslips on the hot plate for 3 minutes before overnight incubation in the humidified chamber at RT.

10. Remove the coverslips from the chamber with fine tweezers and place them back into a 24well plate. Wash coverslips twice 15 minutes with $500 \mu 1$ per well of wash buffer I.

11. Wash coverslips three times 5 minutes with $500 \mu 1$ per well of wash buffer II.

12. Mount coverslips as described in subheading 3.4 step 25-26. 


\subsection{Isolation of genomic DNA for m6A-IP-seq and m6A-dotblot}

1. Cells in a $15 \mathrm{~cm}$ diameter cell culture dish are collected by trypsinization and counted using a TC20 ${ }^{\mathrm{TM}}$ cell counter (see note 9).

2. Wash the cell pellet once in PBS $1 \mathrm{X}$ (see note 10).

3. Extract genomic DNA with the QIAGEN Blood and Cell Culture DNA Midi Kit Genomictip $100 / \mathrm{G}$ according to the manufacturer's instructions but with the following implementation: When the pelleted nuclei are resuspended in buffer G2, add $100 \mu \mathrm{g} / \mathrm{ml}$ RNase A and RNase Cocktail Enzyme Mix to a final concentration of $2.5 \mathrm{U} / \mathrm{ml}$ RNase A and $100 \mathrm{U} / \mathrm{ml}$ RNase $\mathrm{T} 1$ and incubate for at least an hour (see note 11).

4. Measure the DNA concentration (see note 12).

\section{7. m6A-IP-seq procedure}

1. Dilute $20 \mu \mathrm{g}$ of genomic DNA from step $\mathbf{3 . 6}$ in $300 \mu \mathrm{l}$ of ddH2O (final concentration of $66.7 \mathrm{ng} / \mu \mathrm{l}$ ) and transfer to a $1.5 \mathrm{ml}$ polypropylene TPX tube. Sonicate the DNA using a sonicator into fragments of 200-400bp (see note 13).

2. Check the sonication efficiency by loading $500 \mathrm{ng}$ to $1 \mu \mathrm{g}$ of sheared DNA on a $2 \%$ agarose gel (Fig. 1A).

3. Save $1 \%$ of the sample as input fraction.

4. If library preparation is done at a sequencing facility, go straight to step 8 (see note 14).

5. $10 \mu \mathrm{g}$ of sonicated DNA is end-repaired using the NEBNext End-repair module from NEB (2 reactions per $10 \mu \mathrm{g}$ of DNA) according to the manufacturer's instructions with the following modification: reagents volumes are adapted for a final reaction volume of $100 \mu 1$ instead of the $50 \mu 1$ advised by the manufacturer.

6. End-repaired DNA is subsequently purified using AMPureXP beads according to the manufacturer's instructions.

7. End-Repaired DNA is A-tailed using the NEBNext A-tailing module from NEB according to manufacturer's instructions. 
8. Repeat step 6.

9. Double stranded TruSeq Illumina adapters are ligated to DNA using the NEBNext Ligation module according to manufacturer's instructions.

10. Repeat step 6.

11. Pool back together the $10 \mu \mathrm{g}$ of End-repaired, A-tailed and adapter-ligated DNA samples and dilute in TE buffer up to $360 \mu 1$. Denature $10 \mathrm{~min}$ at $95^{\circ} \mathrm{C}$.

12. Snap cool on ice for 10 minutes.

13. Supplement the samples with $10 \mathrm{X}$ m6A-IP buffer to a final concentration of $1 \mathrm{X}$.

14. Add $2.5 \mu \mathrm{g}$ of anti m6A antibody.

15. Rotate overnight at $4^{\circ} \mathrm{C}$.

16. If using magnetic beads, the following steps can be performed with the help of a magnetic rack.

17. Prepare the protein $\mathrm{A} / \mathrm{G}$ coated magnetic beads. Ensure that beads are well resuspended in their buffer in the original vial. We use $20 \mu 1$ per sample. In a $1.5 \mathrm{ml}$ Eppendorf tube, pipette enough beads for all samples. Gently remove the storage buffer and wash the beads with 1 $\mathrm{ml}$ of pre-blocking buffer. Rotate for an hour at $4^{\circ} \mathrm{C}$, then gently remove the pre-blocking buffer to resuspend the beads in the original pipetted volume with $1 \mathrm{X}$ m6A-IP buffer.

18. Add $20 \mu 1$ of beads to each sample.

19. Rotate at $4^{\circ} \mathrm{C}$ for 3 hours.

20. Gently remove and discard the unbound fraction (see note 15).

21. Wash the beads four times with $1 \mathrm{ml}$ of $1 \mathrm{X}$ m6A-IP buffer and invert the tube a few times between washes.

22. Resuspend input and beads samples in $150 \mu$ of digestion buffer supplemented with 300 $\mu \mathrm{g} / \mathrm{ml}$ of proteinase $\mathrm{K}$.

23. Incubate three hours with shaking at $50^{\circ} \mathrm{C}$. Remove the beads and save the eluate.

24. Purify DNA of the input and eluate fractions by standard phenol/chloroform/isoamyl alcohol extraction and resuspend in $21 \mu 1$ of dd 20 .

25. Measure DNA concentration using Qubit fluorometer. 
26. Half of the purified DNA is amplified for 10 cycles using the KAPA Hifi DNA polymerase and the P5 and P7 Illumina primers according to the manufacturer's instructions. Amplified DNA is purified using AMPureXP beads according to the manufacturer's instructions.

27. The libraries can subsequently be send to a sequencing facility.

\section{8. m6A-dotblot}

1. Dilute between 20ng and $1 \mu \mathrm{g}$ of genomic DNA from step 3.6 or isolated DNA regions (see next section 3.9) in $2 \mathrm{XSSC}$ to reach a volume of 100 to $200 \mu 1$ (see note 16).

2. Prepare Whatman filter paper by soaking it into $2 \mathrm{XSSC}$. The Whatman paper must be of equal size of the dotblot apparatus.

3. Prepare the membrane by sequential soaking into $\mathrm{ddH} 2 \mathrm{O}$ then $2 \mathrm{XSSC}$ for at least $5 \mathrm{~min}$ for equilibration. The membrane must be of equal size of the dotblot apparatus.

4. Mount the dotblot apparatus assembling the Whatman paper and the membrane according to the manufacturer's instructions.

5. Heat denature samples at $98^{\circ} \mathrm{C}$ for 10 minutes and snap cool on ice for 10 minutes.

6. Load DNA samples on the membrane via vacuum blotting. Once the wells are empty wash twice with 2XSSC.

7. Remove the membrane from the apparatus using tweezers and place it onto a Whatman paper (DNA facing up) saturated with denaturing solution for 10 minutes at RT.

8. Remove the membrane with tweezers and place it onto a Whatman paper (DNA facing up) saturated with neutralizing solution for 10 minutes at RT.

9. Remove excess of liquid by gently blotting on dry Whatman paper.

10. Crosslink with a UV cross-linker. We usually use $70000 \mu \mathrm{J} / \mathrm{cm}^{2}$.

11. Block for 1 hour at RT in $50 \mathrm{ml}$ of blocking solution.

12. Incubate with the m6A antibody $1 / 1000$ in blocking solution overnight at $4^{\circ} \mathrm{C}$.

13. Wash the membrane three times 10 minutes in PBST.

14. Incubate with the HRP-secondary antibody $1 / 5000$ in blocking solution for $45 \mathrm{~min}$ at RT.

15. Repeat step 13. 
16. Reveal the membrane using the Western ECL substrate according to the manufacture's instruction. Chemiluminescence signal obtained is analysed using the ChemiDoc Imaging System.

\section{9. m6A-dotblot on isolated DNA regions: example of telomere purification by TeloCapture.}

1. To release intact telomeric fragments, digest $50 \mu \mathrm{g}$ of genomic DNA from step $\mathbf{3 . 6}$ with AluI, HinfI, HphI and MnlI $(0.5 \mathrm{U} / \mu \mathrm{g})$ restriction enzymes in a $300 \mu 1$ reaction volume overnight at $37^{\circ} \mathrm{C}$ (see note 17). An example of the migration pattern is shown Fig. 1B.

2. Adjust reaction to $1 \mathrm{X}$ SCC and $0.1 \%$ Triton X-100 by adding $15 \mu 1$ of $20 \mathrm{X}$ SCC and $3 \mu 1$ of Triton X-100 10\%.

3. Add 3.5 pmoles of the biotinylated telomere oligonucleotide per sample. If the oligo is at the standard $100 \mu \mathrm{M}$ concentration, we recommend to make a $1 / 100$ dilution then add 3.5 $\mu 1$ to each sample.

4. Anneal the oligos by controlled stepwise cooling from $80^{\circ} \mathrm{C}$ to $25^{\circ} \mathrm{C}\left(1^{\circ} \mathrm{Cmin}-1\right)$ using a thermocycler.

5. If using magnetic beads, the following steps can be performed with the help of a magnetic rack to collect the beads.

6. During the annealing step prepare the streptavidin-coated magnetic beads. Ensure that beads are well resuspended in their buffer in the original vial. We use $18 \mu 1$ of beads per sample. In a $1.5 \mathrm{ml}$ Eppendorf tube, pipette enough beads for all samples. Pre-wash once in PBST 1X. Block beads by adding $1 \mathrm{ml}$ of $5 \mathrm{X}$ Denhardt solution and incubate for one hour at $4{ }^{\circ} \mathrm{C}$ on a rotating wheel. Resuspend beads in the original pipetted volume with 1X PBST.

7. After annealing, save $3 \mu 1$ or $10 \mu 1$ (i.e. $3-10 \%$ of the starting material) of the sample as input.

8. Add $18 \mu 1$ of prepared beads to each sample.

9. Rotate overnight at $4{ }^{\circ} \mathrm{C}$.

10. Gently remove and discard the unbound fraction (see note 15).

11. Wash the beads four times with $1 \mathrm{ml}$ of wash buffer I and invert the tube a few times between washes. 
12. Wash the beads once with wash buffer II.

13. Resuspend bead in $50 \mu 1$ of elution buffer and elute telomeric DNA by incubating at $50^{\circ} \mathrm{C}$ for 20 minutes gently rotating the tube. Remove the beads and save the eluate.

14. Step 13 may be repeated once (optional).

15. Measure DNA concentration using Qubit.

16. Perform the dotblot as indicated in steps 3.8 (see note 18).

\section{$4 \quad$ Notes.}

1. M.EcoGII constructs are stably expressed in cells using retroviral transduction. Prepare one $10 \mathrm{~cm}$ dish of Phoenix for each transduction you wish to perform.

2. Prepare one $10 \mathrm{~cm}$ dish for each transduction you wish to perform.

3. After retroviral cell transduction, the expression cassettes will randomly integrate into the host genome for stable expression. The M.EcoGII constructs that we generated (see material section) were cloned into the pRetroX-PTuner plasmid (Clontech) that allows the regulation of the amount of the expressed protein of interest. The vector encodes a $12 \mathrm{kDa}$ destabilization domain (DD) that is expressed as a N-terminal tag on all M.EcoGII constructs and causes their rapid degradation via the proteasome. The DD-tagged protein can be rapidly stabilized by addition of Shield-1, a permeable molecule that will bind the DD tag and prevent the proteasomal degradation. Although we found that 6-7 hours of induction was sufficient to induce significant methylation of genomic DNA, experiments that do not require short induction time should be carried out after 24 hours of induction to increase the signal to noise ratio. It is important to note that constitutive overexpression should be avoided as it will result in permanent m6A methylation. We strongly advise to include a condition with no Shield-1 treatment to test for background methylation and efficiency of the induction. As Shield-1 is solubilized in Ethanol, add the corresponding amount of Ethanol in the non-induced samples. 
4. Fixation is a crucial step. Extended fixation may result in antigen masking therefore decreasing the primary antibody efficiency. Also, for some specific proteins the percentage of paraformaldehyde used and/or fixation time may be adapted.

5. m6A immunofluorescence when used to detect methylated DNA requires an RNase treatment. Indeed, mRNA m6A methylation is a very abundant modification in eukaryotic cells. If not removed it will automatically result in a high fluorescence background masking the localization of methylated DNA.

6. This step will allow a better accessibility of m6A by the anti-m6A antibody.

7. This step is required to fix the antibodies for subsequent PNA hybridization steps.

8. At this stage, the coverslips can be stored for a couple of days in the dark in $1 \mathrm{X}$ PBS at $4^{\circ} \mathrm{C}$.

9. Any other cell counting apparatus can be used. The key point is to have a clear idea of the amount of cells harvested for each condition. For example, an excess of cells may impede genomic DNA extraction by cloaking the columns used. Conversely, a low starting amount of cells may result in a sub-optimal DNA yield for high throughput sequencing or a suboptimal telomere yield at the end of the Telocapture hence resulting in a poor signal on the slot-blot membrane.

10. At this stage, the cell pellets can be stored at $-20^{\circ} \mathrm{C}$ for up to 2 months.

11. Using commercially available kits for genomic DNA extraction is a time saver. However, standard protocol can also be used.

12. At this point, genomic DNA can be stored at $-20^{\circ} \mathrm{C}$ for a least a year.

13. We perform this step in the lab using a Bioruptor Plus apparatus from Diagenode equipped with a water cooler. Sonication was performed using the following settings: 40 cycles 30 s ON, 60s OFF, low power.

14. As mentioned in note 6 , the m6 A specific antibody has a better affinity for m6A on denatured DNA. As Illumina adaptors need to be added to double-stranded DNA, the steps of End-repair, A-tailing and ligation need to be performed before the immunoprecipitation step.

15. The unbound fraction can be collected as well for further analysis if needed. 
16. i) To load DNA on the membrane using the dot-blot apparatus, the volume of the sample should ideally be between 100 and $200 \mu 1$. We don't recommend loading less than $50 \mu 1$, as air bubbles can form in the well that may result in unequal spreading of the DNA. ii) The amount of genomic DNA to load can vary between experiments. We recommend loading several amounts to test the linearity of the m6A signal later on.

17. It is good practice to check digestion efficiency by running an aliquot of digested DNA (usually $1-2 \mu \mathrm{g}$ ) on a $2 \%$ agarose gel.

18. It is possible to assess telomere capture efficiency using a Q-PCR approach (Cawthon et al).

\section{Acknowledgment}

We would like to thank all the members (past and present) of the Crabbe's lab for helpful discussions especially Sonia Stinus Ruiz de Gauna for critical reading of the manuscript. This work was supported by an ATIP starting grant from CNRS in the framework of Plan Cancer 2014-2019 (to L.C.), the ANR Tremplin ERC teloHOOK (ANR-16-TERC-0028-01 to L.C.), and a European Research Council (ERC) grant (TeloHOOK, 714653 to L.C.).

\section{References}

1. Orlando V, Strutt H, Paro R (1997) Analysis of chromatin structure by in vivo formaldehyde crosslinking. Methods 11:205-214. doi: 10.1006/meth.1996.0407

2. Sobecki M, Souaid C, Boulay J, et al (2018) MadID, a Versatile Approach to Map Protein-DNA Interactions, Highlights Telomere-Nuclear Envelope Contact Sites in Human Cells. Cell Rep 25:2891-2903.e5. doi: 10.1016/j.celrep.2018.11.027

3. van Steensel B, Delrow J, Henikoff S (2001) Chromatin profiling using targeted DNA adenine methyltransferase. Nat Genet 27:304-308. doi: 10.1038/85871

4. Kind J, Pagie L, de Vries SS, et al (2015) Genome-wide Maps of Nuclear Lamina Interactions in Single Human Cells. Cell 1-15. doi: 10.1016/j.cell.2015.08.040

5. Guelen L, Pagie L, Brasset E, et al (2008) Domain organization of human chromosomes revealed by mapping of nuclear lamina interactions. Nature 453:948-951. doi: 10.1038/nature06947

6. Kind J, van Steensel B (2014) Stochastic genome-nuclear lamina interactions: modulating roles of Lamin A and BAF. nucleus 5:124-130. doi: 10.4161/nucl.28825 
7. Filion GJ, van Bemmel JG, Braunschweig U, et al (2010) Systematic protein location mapping reveals five principal chromatin types in Drosophila cells. Cell 143:212-224. doi: 10.1016/j.cell.2010.09.009

8. Murray IA, Morgan RD, Luyten Y, et al (2017) The non-specific adenine DNA methyltransferase M.EcoGII. Nucleic Acids Res 46:840-848. doi: 10.1093/nar/gkx1191

\section{Figure Legends}

Fig1: Migration patterns of sonicated or digested human genomic DNA. (A) $1 \mu \mathrm{g}$ of human genomic

DNA before (-) or after sonication (+) was loaded on a 2\% agarose gel. (B) 1 (lane 1) or 2 (lane 2) $\mu \mathrm{g}$ of human genomic DNA was digested overnight with AluI, HinfI, HphI and MnlI $(0.5 \mathrm{U} / \mu \mathrm{g})$ restriction enzymes and loaded on a $2 \%$ agarose gel. 
A

human genomic DNA

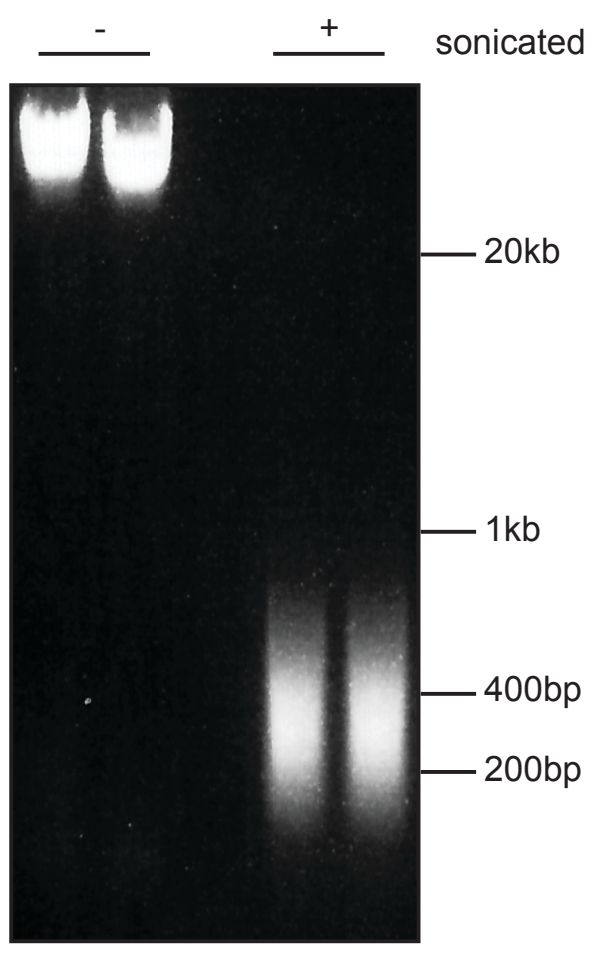

B

Digested human genomic DNA

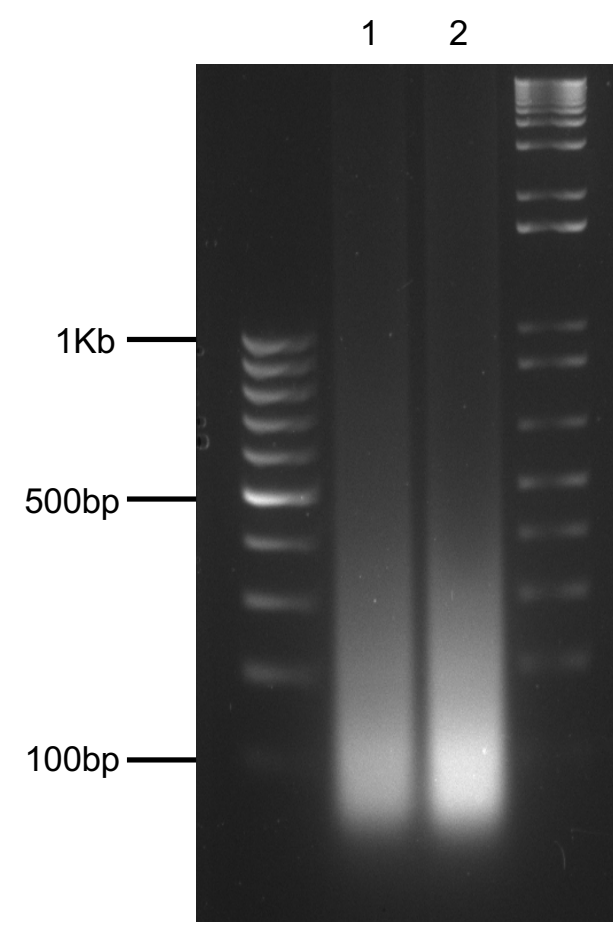

